
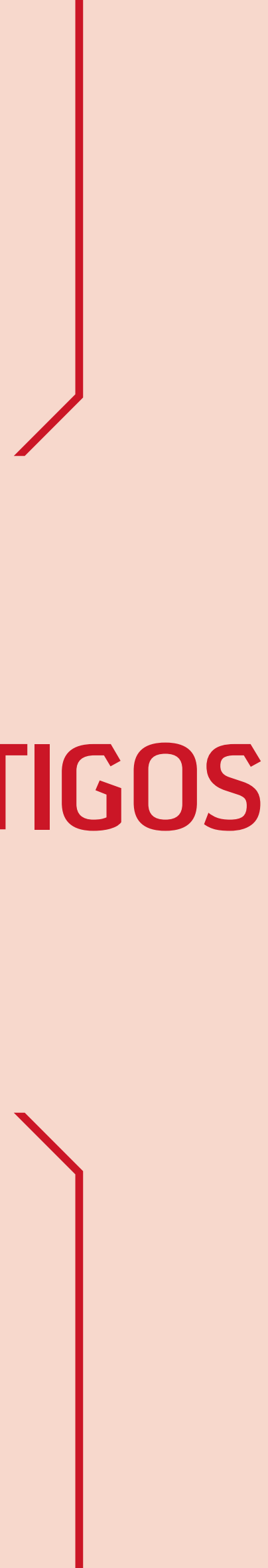


\section{CONCORDÂNCIA VERBAL COM ESTRUTURAS PARTITIVAS: A REGRA GRAMATICAL VERSUS O USO}

\section{MARCUS VINIICIUS PEREIRA DAS DORES ${ }^{1}$}

Mestrando em Estudos Linguísticos pela Universidade Federal de Minas Gerais (UFMG), Belo Horizonte, MG, Brasil.

E-mail: marcusdores@hotmail.com

\section{CHRISTIANE BENONES DE OLIVEIRA ${ }^{2}$}

Mestranda em Letras pela Universidade Federal de Ouro Preto (UFOP), Ouro Preto, MG, Brasil. E-mail: christianebenonesoliveira@gmail.com

\section{ERICK SOARES DRUMOND}

Graduando em Letras pela Universidade Federal de Ouro Preto (UFOP), Ouro Preto, MG, Brasil. E-mail: erick_drumond@hotmail.com

\section{Resumo}

O objetivo principal deste artigo é apresentar os resultados de um estudo preliminar sobre a concordância verbal com estruturas partitivas. A partir da análise de provas de redação do vestibular de 2010 da Universidade Federal de Ouro Preto (UFOP) dos candidatos aos cursos de Biologia e Letras, procedeu-se ao levantamento das ocorrên-

1 Bolsista CNPq.

2 Bolsista FAPEMIG. 
cias dessa estrutura. Após esse levantamento, cada estrutura foi analisada de maneira a verificar se a concordância fora feita com o núcleo do Sintagma Nominal (SN) ou com o núcleo do Sintagma Preposicional (SPrep) à esquerda do núcleo do SN.

\section{Palavras-chave}

Concordância verbal. Partitivas. Núcleo do Sintagma Nominal.

\section{INTRODUÇÃO}

O objetivo do presente artigo, que é parte do trabalho final da disciplina Sociolinguística (LET821), ${ }^{3}$ do departamento de Letras da Universidade Federal de Ouro Preto (UFOP), ministrada pela professora Dra. Soélis Teixeira do Prado Mendes, é analisar, com base nos estudos sociolinguísticos, como a concordância verbal com estruturas partitivas vem sendo feita pelos usuários da língua, ou seja, com qual sintagma o verbo faz concordância.

Para o estudo comparativo desse fenômeno, foram definidas quatro etapas: 1. levantar as ocorrências nas provas de redação do vestibular do segundo semestre da UFOP dos cursos de Biologia e de Letras; 2. verificar se algum dado deve ser descartado; 3 . ver com qual termo o verbo concorda; e 4. verificar qual regra prescrita pela gramática normativa foi seguida para estabelecer a concordância.

Para tanto, este texto foi organizado em 3 seções, além desta introdução, das considerações finais e das referências. Em primeiro lugar, foi elaborada uma síntese sobre variação linguística, levando em conta as referências utilizadas durante o curso de Sociolinguística. Como o tema do estudo é verificar com qual sintagma o verbo faz concordância em casos de presença de estruturas partitivas ("maioria", "parte" etc.) no Sintagma Nominal (SN) sujeito, tenciona-se buscar em algumas gramáticas o que é prescrito em relação a essa estrutura. Faz-se uma discussão, nessa linha, sobre a concordância canônica prescrita pela gramática e a concordância facultativa, regida pelo estilo. Por fim, os dados levantados são apresentados em quadros para fim de análise da regra utilizada para concordância.

Segundo preconizam as gramáticas normativas da língua portuguesa, como a Gramática normativa da língua portuguesa (ROCHA, 1962), a Moder-

3 Ementa da disciplina: tópicos em teoria da variação e mudança linguística. 
na gramática portuguesa (BECHARA, 1978), a Novíssima Gramática da Língua Portuguesa (CEGALLA, 1984), a Nova Gramática do Português Contemporâneo (CUNHA \& CINTRA, 1985), a Gramática Resumida (LUFT, 2004), o verbo, de forma geral, deve concordar com o núcleo seu sujeito em número e pessoa. Consultando a Nomenclatura Gramatical Brasileira (NGB), Luft (2004, p. 150) conclui que:

Em português, há a concordância do verbo com o seu sujeito em número e pessoa [...] [contudo,] [a] NGB não se refere às concordâncias anômalas - ideológica, afetiva, por atração -, concordância estilística, etc.

Segundo Cunha e Cintra (2007, p. 513), a forma do verbo é estabelecida com base na ideia que o sujeito deseja expressar. "Deixamos o verbo no singular quando queremos destacar o conjunto como uma unidade. Levamos o verbo ao plural para evidenciarmos os vários elementos que compõem o todo”.

Assim, em (01), a totalidade das palavras está em destaque, enquanto, em (02), os indivíduos que compõem o conjunto de “doidos" são colocados em evidência. ${ }^{4}$

1. “A maioria das palavras continua visível".

2. “A maior parte dos doidos ali metidos estão em seu perfeito juízo".

Segundo Cegala (2008), os exemplos apresentados mostram que a aplicação da regra geral da concordância, como se observa em (01), seria facultativa.

Reduzido é o número de trabalhos no vasto campo dos Estudos Linguísticos que têm por objetivo investigar a concordância verbal com construções partitivas em português. Trabalhos sociolinguísticos podem ser citados, em particular alguns artigos nos quais são apresentados resultados de pesquisas sobre concordância com sujeitos de estrutura complexa, a partir de dados escritos (cf. SCHERRE \& NARO, 1998; NARO \& SCHERRE, 2000; SCHERRE \& NARO, 2002).

Assumindo os pressupostos da Teoria da Variação (LABOV, 1963), partimos da hipótese de que a concordância verbal com partitivas no português brasileiro é condicionada.

4 Todos os exemplos foram retirados de Cegala (2008, p. 455-456). 


\section{VARIAÇÃO LINGUÍSTICA}

A relação entre a linguagem e o homem é um fenômeno inseparável. A constituição da sociedade como conhecemos se dá, entre outros aspectos, por meio da linguagem. Por isso, a importância de se estudar e conhecer profundamente esse mecanismo de comunicação é inerente ao ser humano. As teorias da linguagem tratam de modos diferentes a importância social da língua na vida do homem.

Saussure (1981) apresenta a língua como o principal objeto da Linguística, diferenciando-a da fala, que é objeto de estudos referentes a outras disciplinas. Para o autor, a língua é um fator social da linguagem e uma pessoa sozinha não é capaz de modificá-la. Jakobson (1960) é contra o princípio de homogeneidade postulado por Saussure (1981) e acredita que exista um processo heterogêneo na linguagem, que se manifesta nas situações comunicativas com escolhas feitas pelos falantes. Labov (1963), por sua vez, acredita que o foco dos Estudos Linguísticos deve ser as comunidades de fala. Discordando de Saussure, Labov (1963) ainda afirma que a fala não é caótica ou desmotivada; para ele, a estrutura e a evolução da língua devem ser estudadas no contexto social da comunidade. Para Benveniste (1968), a relação entre língua e sociedade consiste no fato de que a língua serve como instrumento de análise da sociedade.

Uma das propostas das ciências que estudam a mudança linguística, sobretudo da Sociolinguística, é mostrar que a língua não é fixa e que o processo de mudança não ocorre apenas ao longo do tempo. As mudanças na língua ocorrem por múltiplos fatores: contexto social, gênero, idade, região, profissão, grau de escolaridade entre tantos outros aspectos. O conceito de variedade é explicado por Lucchesi e Araújo (2004) ao dizer que "nas comunidades de fala, frequentemente, existirão formas linguísticas em variação, isto é, formas que estão em coocorrência e em concorrência. Daí ser a Sociolinguística variacionista também denominada de Teoria da Variação", que podem ocorrer em qualquer estrutura da língua. Desse modo, pode-se afirmar que a preocupação da Sociolinguística em estudar e descrever a língua em uso é justamente pelo fato de todas as línguas naturais sofrerem variação.

Assim, é possível perceber que a variação linguística se manifesta de muitas formas. Calvet (2002) faz uma classificação das diferentes variações que 
podem ocorrer na língua; são elas: variação diacrônica, sendo aquela que se dá com o passar do tempo e é transmitida por meio das gerações; variação diastrática, aquela que diferencia os grupos sociais; variação diatópica, que está relacionada à variação de uma mesma língua de acordo com as regiões dos falantes. Ilari e Baso (2006) cita ainda a existência da variação diamésica, relacionada ao meio ou veículo em que a informação foi transmitida.

Pode-se perceber a presença de variação em todas as comunidades de fala e, a partir disso, o surgimento de variantes que são "diversas maneiras de se dizer a mesma coisa em um mesmo contexto e com o mesmo valor de verdade" (LUCCHESI \& ARAÚJO, 2004) e que podem ocorrer em qualquer estrutura da língua. Exemplo disso é a marcação de plural do sintagma nominal no português brasileiro: há quem marque o primeiro termo apenas, deixando os outros no singular e há quem marque todas as estruturas da sentença.

3. As menina chegou.

4. As meninas chegaram.

Essa forma de marcar plural no verbo expressa também uma variação na língua, sendo o primeiro exemplo comumente usado em situações cotidianas de fala e o segundo, uma variante formal da língua. O uso de marcação de plural em todos os itens lexicais da estrutura é redundante, haja vista que ao sinalizar a marcação no primeiro elemento a compreensão estará fixada. Embora a não marcação de plural sofra estigmatização, Naro e Scherre (2007) mostram que essa forma de uso não está diretamente ligada ao fator de escolarização, mas à estrutura da língua. Por isso, é mais comum usar a marca de plural em alguns casos e deixar de usá-la em outros. Esse processo, muitas vezes, pode ser explicado por questões de saliência fônica: é mais comum deparar-se com "as blusa" do que com "os ovo". Ainda sobre o fenômeno da concordância variável, vale ressaltar que, mesmo se tratando de um fenômeno diretamente ligado à estrutura do Português Brasileiro, como apontam Naro e Scherre, não se pode desprezar o contexto social e cultural do falante, ou seja, o lado extralinguístico do fenômeno.

No que diz respeito à dicotomia sincronia/diacronia - proposta por Saussure -, a Teoria da Variação as aproxima, “[a]final de contas, para que os sistemas mudem, urge que eles tenham sofrido algum tipo de variação" (TARALLO, 1994 , p. 25). Essa aproximação ocorre pelo fato de que, para analisar uma 
mudança que ocorre no presente, por exemplo, deve-se voltar ao passado para entender historicamente o processo das variantes que propiciaram o surgimento de uma nova forma de uso na língua. Da mesma forma, é possível analisar as formas em uso no presente e projetar possíveis mudanças para o futuro, o que configura uma mudança em tempo aparente. É preciso, portanto, explicar que, de acordo com Labov (1963), nem toda variação implica mudança, mas que toda mudança surgiu de uma variação.

É importante destacar também que não é possível falar em variação e não tangenciar questões relacionadas ao prestígio de um uso em detrimento de outro. O professor Dr. Marcos Bagno vem dedicando várias de suas pesquisas a essas questões. Segundo Bagno (2007, p. 12),

[o] preconceito [linguístico] é alimentado diariamente em programas de televisão e de rádio, em colunas de jornal e revista, em livros e manuais que pretendem ensinar o que é "certo" e o que é "errado", sem falar, é claro, nos instrumentos tradicionais de ensino da língua: a gramática normativa e os livros didáticos.

Dialogando com as questões levantadas por Bagno e Silva (2014), à luz de outros pesquisadores ${ }^{5} \mathrm{da}$ área, afirma que "atualmente as variações estão sendo mais estudadas e mais aceitas, tendo sido a questão do "certo" e do "errado" deslocada para a do mais/menos adequado à situação de comunicação”. Segundo Perini (2009, p. 56), “o gramático vai precisar aprender a dizer o que a língua é, não o que (segundo ele) deveria ser”.

\section{CONCORDÂNCIA EM ESTRUTURAS PARTITIVAS SEGUNDO A GRAMÍ́TICA}

Depois de tudo discutido até aqui, foram levantadas dúvidas como, por exemplo, a existência ou não de uma forma de concordância de estruturas partitivas de mais prestígio que outras e se há um consenso entre os gramáticos acerca do assunto.

Brandão (1963, p. 169) aponta que

5 Cf. Mendes (1985); Perini (2009); Soares (2002); Travaglia (2001).

141 
Um coletivo geral ou partitivo, acompanhando de complemento do plural, claro ou subentendido, pode ter o seu verbo no singular ou plural, mas êste número é o mais comum, sobretudo quando a ação verbal pode atribuir-se separadamente a cada um dos sêres que constituem a coleção [...].

Azeredo (2008, p. 230) diz que “[s]e o sujeito é formado por expressão partitiva do tipo 'a maioria dos candidatos', o verbo concorda ordinariamente com o núcleo sintático da construção", e afirma que a concordância com o núcleo referencial (substantivo) também está correta, porém é apenas uma marca estilística.

Cegalla (2008), por sua vez, concorda quanto à afirmação sobre o uso das duas formas de concordância, mas ressalta que a concordância com o coletivo singular é rigorosamente gramatical, enquanto a concordância com o termo mais próximo é uma tentativa de enfatizar-se a ideia expressa de que o sujeito está no plural. Ao afirmar que "quando o verbo precede o sujeito, [...] a concordância se efetua no singular”, (CEGALLA, 2008, p. 456), ele explica que construções que não sigam a forma convencional de estruturação (sujeito + verbo + predicado) deverão sempre concordar com o núcleo do sintagma nominal, como nas sentenças que seguem:

5. Na sala de jantar estava parte dos convidados.

6. Viajou de carro a maioria dos congressistas.

É possível perceber, nos exemplos acima, que o termo mais próximo do verbo é o núcleo sintático, e não o referencial, o que justifica a concordância apresentada.

Bechara (1999, p. 569) é um pouco mais direto e afirma que "[s]e o sujeito é representado por expressões do tipo 'a maioria de', 'a maior parte de', e um nome no plural, o verbo irá para o singular ou plural”, sem ressaltar as particularidades apresentadas pelos gramáticos citados anteriormente e nem citar alguma outra nova. Cunha e Cintra (2007) e Lima (1996) também partilham dessa opinião, e trazem uma abordagem rápida e direta sobre o tema, apresentando um exemplo para a forma de concordância com o núcleo do sintagma nominal e outro para a concordância com o núcleo referencial. Já Castilho (2010, p. 272) se atém mais à explicação das duas ocorrências, afirmando que aquela na qual o verbo concorda com o núcleo do sintagma nominal "conforma-se com a categoria morfologicamente singular", ressaltando que essa concordân- 
cia pode acontecer também em nível semântico, que é quando a concordância se dá com o núcleo referencial. "Casos como esse são descritos nas gramáticas como concordância ad sensum” (CASTILHO, 2010, p. 272), que é aquela feita de forma livre e em prol do sentido que se deseja alcançar.

\section{APRESENTAÇÃO E ANÁLISE DOS DADOS}

O corpus desta investigação é constituído por 312 provas de redação do processo seletivo para ingresso no segundo semestre de 2010 da Universidade Federal de Ouro Preto. Dessas 312 provas, 185 eram de candidatos ao curso de Biologia e 127 de candidatos ao curso de Letras. Como já foi mencionado anteriormente, o objetivo desta pequena pesquisa é observar a concordância do verbo com estruturas partitivas. Apesar do alto número de provas analisadas, a variável pesquisada foi encontrada em apenas 16 delas. Os quadros abaixo, separados por curso, trazem a transcrição das sentenças em que essa estrutura se fez presente e apontam se o verbo está no singular ou no plural.

\section{Quadro 1 - Curso: Biologia}

\section{Ocorrência da variável}

Um exemplo clássico é o Big Brother Brasil um reality show onde um grupo de pessoas têm suas vidas expostas para toda uma nação.

A maioria das pessoas dos tempos atuais querem os seus quinze minutos de fama, muitos fazem coisas absurdas para conseguir aparecer na mídia, querem tornar a sua vida pública custe o que custar, seja pelo dinheiro, pela fama ou até mesmo por alguma carência.

A maioria das pessoas querem ser famosas, pensando que assim serão bem vistas e que conquistarão qualquer coisa que quiserem. Hoje a maioria das pessoas possuem uma página de relacionamento na internet, blog e/ou até twister (que até alguns famosos tem).

A maioria das pessoas fazem coisas realmente inusitadas e, muitas vezes, estranhas e perigosas, para chamar a atenção da mídia. Flash, fama e dinheiro, são o que a maioria das pessoas anseiam ser um profissional competente já não é inspiradouro, a fama, o reconhecimento em massa, seja por méritos ou escândalos são os valores que têm sido importantes.
Verbo

\begin{tabular}{|c|c|}
\hline \multicolumn{2}{|c|}{ Verbo } \\
\hline Singular & Plural \\
$\mathrm{X}$ \\
$\mathrm{X}$ \\
$\mathrm{X}$ \\
$\mathrm{x}$ \\
$\mathrm{x}$
\end{tabular}

(continua) 
Quadro 1 - Curso: Biologia (conclusão)

Para pessoas "normais" já é difícil ter liberdade e privacidade, as pessoas famosas sofrem muito mais com esse problema, elas não podem sair nas ruas sem serem notadas e as vezes até perseguidas por paparazzis, além disso a maioria dos famosos têm que andar com seguranças para garantirem proteção para fazer atividades consideradas normais como fazer compras ou irem a um restaurante.

Isso porque a maior parte dos seres humanos carregam consigo uma vontade inata de se exporem, nem que seja de forma negativa a fim de se tornarem conhecidos.

A maioria deles não possui condição de levar uma vida normal, visto que suas atitudes são constantemente copiadas por seus fãs e vigiadas pela imprensa, que procura seus atos falhos para serem publicados e criticados.

Fonte: Elaborado pelos autores.

Quadro 2 - Curso: Letras

\section{Curso: Letras}

\section{Ocorrência da variável}

A fama, essa ideia de uma vida luxuosa, de gente bonita, de fotografias, ser capa de revistas e de dar autógrafos é o que grande parte das pessoas almejam.

A exposição da vida particular está cada dia mais presente no cotidiano, a maioria das pessoas por vários motivos, seja busca pela fama, reconhecimento ou dinheiro são capazes de se expor ao ridículo na maioria das vezes para alcançar seus objetivos.

É, hoje todas ou a maioria das pessoas estão em busca de uma vida cheia de sucesso, mas mal sabem elas o quanto essa exposição interfere na vida particular.

A maioria dos famosos não conseguem ter vida própria.

Grande parte destas informações pessoais podem ser facilmente encontradas na internet.

\section{Verbo}

\begin{tabular}{|c|c}
\hline Singular & Plural \\
$\mathrm{X}$ \\
$\mathrm{X}$ \\
$\mathrm{x}$ \\
$\mathrm{x}$
\end{tabular}

Fonte: Elaborado pelos autores.

Dizer que o verbo está no singular significa dizer que ele concorda com o núcleo do SN. Em contrapartida, dizer que ele está no plural é o mesmo 
que dizer que ele está em concordância com o núcleo referencial, termo mais próximo. Foram encontradas 16 ocorrências, conforme dito anteriormente, mas os quadros trazem apenas 14 delas. Isso porque optou-se por descartar as ocorrências:

5. "Existem artistas que buscam esconder sua vida pessoal, porém a maioria não tem esse costume.”

6. "A maioria dos famosos não tem vida própria."

As frases (05) e (06) foram extraídas de diferentes provas, nas quais o verbo concorda com o núcleo do SN. É importante lembrar que a única distinção entre as formas singular e plural da terceira pessoa do verbo 'ter' é o acento diferencial (circunflexo). No primeiro caso, não foi possível perceber se o candidato conhecia essa norma, já que não foi encontrada qualquer outra ocorrência semelhante no restante da redação. Já no segundo caso, o descarte é justificado tanto pela ocorrência simultânea das formas plural e singular, realizadas nas páginas de rascunho e redação definitiva, respectivamente, quanto pelo fato de as demais construções próximas à destacada também se apresentaram na forma plural, o que reitera o objetivo do candidato de possivelmente realizar a concordância com o núcleo referencial.

Como já foi dito, o contexto textual prova que o candidato conhecia a forma plural do verbo e, por isso, fez todas as demais construções daquele período também no plural, mas na redação definitiva realizou a forma singular do verbo, isto é, sem o acento diferencial. Ambos os casos deixam claro que o verbo 'ter' é um verbo com ocorrência complexa, pois não há distinção fonológica entre o singular e plural da terceira pessoa, diferentemente dos demais verbos destacados. Essa particularidade caracteriza um uso carente de análise mais precisa, o que não é o foco desta pesquisa.

\section{CONSIDERAÇÕES FINAIS}

A discussão proposta neste artigo teve como objetivo indicar resultados obtidos com a pesquisa sociolinguística sobre a concordância verbal com SN composto de partitivas e substantivo plural. Após toda a discussão apresentada, que teve início com escolha do corpus dessa pesquisa, é possível perceber, 
quase que por unanimidade de escolha dos candidatos, que a concordância mais comum do verbo com estruturas partitivas é aquela que se faz com o núcleo do Sintagma Preposicional (SPrep) à esquerda do núcleo do SN, ou seja, com o termo mais próximo do verbo em construções que seguem a estrutura padrão do português brasileiro. No entanto, a análise das gramáticas deixa claro que as duas formas de concordância estão adequadas e, portanto, são igualmente aceitas. É importante levar em consideração que os dados analisados são oriundos da escrita e que, na oralidade esses resultados, possivelmente, seriam diferentes.

Uma interpretação que fazemos do fenômeno aqui discutido é que essa variação de concordância só ocorre porque a estrutura partitiva fornece uma “ambiguidade", ou seja, sintaticamente o sujeito da frase está no singular, já semanticamente ele está no plural.

Certamente, ainda há muito que se explorar em relação a essas estruturas, especialmente quando estão associadas a verbos irregulares, como o verbo 'ter', muito bem exemplificado pelas ocorrências apresentadas na análise dos dados. Outro fenômeno interessante também observado é a baixa ocorrência desse tipo de estrutura se comparado ao número de vezes em que os candidatos optaram por fazer construções com estruturas partitivas, visto que foi analisado um número significativo de provas.

\section{Verbal agreement in partitives: grammatical rule versus usage}

\section{Abstract}

This paper aims at presenting results from a preliminary study concerning verbal agreement in partitive phrases in Brazilian Portuguese. Using written vestibular exams from the Universidade Federal de Ouro Preto (UFOP) 2010 admission process (exams of Biology and Language and Literature degree candidates), the occurrences of partitive phrases were selected. After this survey, each structure was analyzed in order to verify whether the verb agreed with the nominal group head or with the prepositional phrase before it.

\section{Keywords}

Verbal agreement. Partitives. Heading. Nominal group. 


\section{REFERÊNCIAS}

AZEREDO, J. C. de. Gramática Houaiss da Lingua Portuguesa. 2. ed. - São Paulo: Publifolha, 2008, p. 230-232.

BAGNO, M. Preconceito linguístico - o que é, como se faz. 49. ed. São Paulo: Edições Loyola, 2007.

BRANDÃO, C. Sintaxe Clássica Portuguesa. Belo Horizonte: Imprensa da Universidade de Minas Gerais, 1963.

BECHARA, E. Moderna gramática portuguesa. 37. ed. ver. e ampl. Rio de Janeiro: Lucerna, 1999.

BENVENISTE, E. Estrutura da língua e estrutura da sociedade. In: BENVENISTE, E. (Org.). Problemas de linguística geral II. São Paulo: Cia. Editora Nacional/EDUSP, 1989 (título original, 1968).

CALVET, L. J. Sociolinguística: uma introdução crítica. São Paulo: Parábola, 2002.

CEGALLA, D. P. Novíssima Gramática da Língua Portuguesa. 48. ed. rev. São Paulo: Companhia Editora Nacional, 2008.

CUNHA, C.; CINTRA, L. F. L. Nova Gramática do Português Contemporâneo. 4. ed. rev. e ampl. Rio de Janeiro: Lexicon Editora Digital, 2007.

JAKOBSON, R. Linguística e poética. In: JAKOBSON, R. (Org.). Linguística e comunicação. São Paulo: Cultrix, 1970.

LABOV, W. Sociolinguistics patterns. Philadelphia: University of Pennsylvania Press, 1963.

LIMA, C. H. da R. Gramática normativa da língua portuguesa. 27. ed. Rio de Janeiro: José Olympio, 1996.

LUCCHESI, D.; ARAÚJO, S. A Teoria da Variação Linguística. Vertentes do Português Popular do Estado da Bahia. Projeto Vertentes, 2004. Disponível em: <http://www. vertentes.ufba.br/a-teoria-da-variacao-linguistica>. Acesso em: 22 out. 2016.

LUFT, C. P. Gramática Resumida. Rio de Janeiro: Globo, 2004.

MENDES, F. Grammatica portugueza pelo methodo confuso. 4. ed. Vitória: Rocco Fundação Ceciliano Abel de Almeida/UFES, 1985.

NARO, A. J.; SCHERRE, M. M. P. Origens do português brasileiro. São Paulo: Parábola, 2007.

NARO, A. J.; SCHERRE, M. M. P. A hierarquização do controle da concordância no português moderno medieval: o caso de estruturas sujeito simples. In: GROBE, S.; ZIMMERMANN, K. (Eds). O português brasileiro: pesquisas e projetos. C. 17. Frankfurt am Main: TFM, 2000., p. 135-165. 
PERINI, M. A. Sofrendo a Gramática. 3. ed. São Paulo, 2009.

SAUSSURE, F. de. Curso de linguística geral. 3. ed. São Paulo: Cultrix, 1981.

SCHERRE, M. M. P.; NARO, A. J. Restrições sintáticas e semânticas no controle da concordância verbal em português. Fórum Linguístico, v. 1, 1998, p. 45-71.

SCHERRE, M. M. P.; NARO, A. J. Uma reflexão sociolinguística sobre o conceito de erro. In: BAGNO, M. (Org.). Linguística e norma. São Paulo: Loyola, 2002.

SILVA, B. A. da. Subvertendo a gramática. Revista Caletroscópio,, v. 2, n. 2, p. 123 -148, 2014. Disponível em: <http://www.ichs2.ufop.br/caletroscopio/revista/index. php/caletroscopio/article/view/26>. Acesso em: 26 out. 2016.

SOARES, M. Português na escola: história de uma disciplina curricular. In: BAGNO, M. (Org.). Linguística da norma. São Paulo: Edições Loyola, 2002.

TARALLO, F. A pesquisa sociolinguística. São Paulo: Ática, 1994.

TRAVAGLIA, L. C. Gramática e interação: uma proposta para o ensino de gramática no $1^{\circ}$ e $2^{\underline{o}}$ graus. 6. ed. São Paulo: Cortez, 2001.

Recebido em 27-03-2017.

Aprovado em 30-07-2017. 